Original Research Paper

\title{
Simulation of Production of Anhydrous Bioethanol using Glycerol and 1-Butyl-3-Methylimidazolyl-Tetrafluoroborate in the Aspen Plus Simulator
}

\author{
${ }^{1 *}$ José Izaquiel Santos da Silva, ${ }^{1}$ Lílian da Silva Félix, ${ }^{1}$ Mariana Martins Vieira, \\ ${ }^{1}$ Victória Caroline Veloso Meireles, ${ }^{2}$ Edilailsa Januário de Melo and ${ }^{1}$ Rogério Alexandre Alves de Melo \\ ${ }^{1}$ Institute of Science and Technology, \\ Federal University of Jequitinhonha and Mucuri Valleys (ICT/UFVJM), Diamantina - MG, Brazil \\ ${ }^{2}$ Chemical Engineering College, Campinas State University (FEQ/UNICAMP), Campinas - SP, Brazil
}

\author{
Article history \\ Received: $30-10-2020$ \\ Revised: 22-11-2020 \\ Accepted: 27-11-2020 \\ Corresponding Author: \\ José Izaquiel Santos da Silva \\ Institute of Science and \\ Technology, Federal University \\ of Jequitinhonha and Mucuri \\ Valleys (ICT/UFVJM), \\ Diamantina - MG, Brazil \\ Email: izaquiel@ict.ufvjm.edu.br
}

\begin{abstract}
Biofuels are present in the global scenario as an energy source derived from organic biomass, representing an economic and environmental alternative. They are a renewable source of energy with low rates of pollutants emissions and, consequently, less carbon dioxide is released into the atmosphere. The obtaining of bioethanol is originated from a fermentation process, in which a multi-component mix is generated and the anhydrous bioethanol is separated. To obtain such compounds, some operations are required, such as extractive distillation, where solvents are added in order to "break" the ethanol-water azeotrope. In the present work two solvents were used: Glycerol and the ionic liquid [BMIM][BF4]. Starting from a multi-component mixture composed by ethanol, water, acetic acid and isoamyl alcohol, the bioethanol purification process was simulated using the computational tool Aspen Plus® simulator. Through a comparative analysis, it was possible to determine which solvent presented the best performance, where operational parameters such as the reflux ratio, distillate rate and the solvent flow were analyzed. The purity degree of $99.7 \%$ in mass and an approximate production of $2764 \mathrm{~kg} / \mathrm{h}$ of anhydrous bioethanol were fixed and the results showed that glycerol was the solvent that presented greater economic and environmental viability for the process, considering the operational parameters mentioned above.
\end{abstract}

Keywords: Azeotrope, Anhydrous Bioethanol, Computational Simulation, Aspen Plus ${ }^{\circledR}$

\section{Introduction}

The world scene requires the use of new sources of energy that meet economy and, specially, environmental requirements in a sustainable way. In this context, the applicability of biofuel to meet such demand stands out. Besides being produced by any biomass that contains sugar or starch in relevant quantity, biofuel is a renewable fuel and emits lower levels of pollutants into the atmosphere (Masson et al., 2015).

The bioethanol produced in Brazil is generated from sugar cane biomass. One of the primordial steps in bioethanol production is the fermentation. Thus, at the end of this step, fermented wort is generated, which is pumped into tanks that feed the centrifugal separator, where the wort is separated in two parts: The yeast and the wine. The wine consists of bioethanol, water and other compounds, such as higher alcohols, furfural, acetic aldehyde, succinic and acetic acids, glycerol, among others (Zanardi and Junior, 2016).

The wine produced in the fermentation process presents a multicomponent nature, being considered, in this study, a mix of bioethanol, water, acetic acid and isoamyl alcohol. From this impure material, anhydrous bioethanol is separated by extractive distillation with a purity degree of $99.6 \%$ in mass, as established by the Technical Regulation ANP n³/2011 (ANP, 2011).

The anhydrous bioethanol has been of great interest to chemical companies due to its potential as solvent for many processes, as well as for being raw material on several chemical syntheses (Zhu et al., 2016). However, to obtain anhydrous bioethanol, distillation techniques are 
required due to the azeotrope phenomenon present in the original mixture.

If the system has azeotropes or compounds with the same boiling temperatures, the conventional distillation process becomes impracticable, being necessary to resort to other methodologies. One common technology used by chemical industries on such systems, like bioethanol/water, is the extractive distillation (Zubir et al., 2017). In this study, simulation predicts that the solvent will be added into the system, changing the relative volatility of the compounds, with the purpose to prevent the formation of the azeotrope, enabling low energy consumption. This process stands out for its low energy consumption. Currently, the solvents used on extractive distillation to obtain anhydrous alcohol are glycerol, glycol, ionic liquid, salts, among others (Navarrete-Contreras et al., 2014).

There are countless solvents that can be applied to bioethanol/water system to obtain anhydrous ethanol, being glycerol a viable alternative. According to (Teng et al., 2016), the use of glycerol is encouraged because it is a byproduct of biodiesel production, which represents around $10 \%$ in weight of the production, causing a huge increase of its stock. The glycerol is a non-toxic compound and its use as a separation agent for dehydration combined with ethanol may suggest an important concept of integrated process, besides ensuring the global process sustainability (Souza et al., 2013).

Ionic Liquids (IL) is outstanding compounds with significant advantages. Although ionic liquids may have an environmental impact when released to water sources, they have characteristics that point them as green solvents. Ionic liquids also stand out for having insignificant vapor pressures, which favors the non-release of toxic gases into the atmosphere and makes them more environmentally friendly (Zhou et al., 2013; Zhao et al., 2014). Ionic liquids typically consist of a large organic cation and an inorganic anion. Currently, IL are being employed as solvents in extractive distillation process, where they act as mass transfer or electrochemical agents (Zarca et al., 2015) due to their flammability, negligible vapor pressure, high selectivity for polar and nonpolar compounds and their toxicity (Pieczyńska et al., 2015). Their properties can be altered by the combination of cation, anion and cation alkyl chain length (Ruivo et al., 2010; Kulajanpeng et al., 2016).

The selection of the solvent is primordial to extractive distillation process, so this factor should be considered. One of the factors for the selection of the ionic liquid is the availability of experimental Vapor-Liquid Equilibrium (VLE) data of the system to be studied, such as water/ethanol/IL system, as well as the physicochemical properties of the ionic liquid to be used. Relative volatility and selectivity are some of the criteria to be considered for the choice of the solvents (Zhu et al., 2016). In addition, properties such as viscosity, toxicity, chemical stability, flammability, recyclability and cost are other important properties to be considered when choosing ionic liquids, being viscosity the main criterion for cation and anion selection (Kuhlmann et al., 2007), since this parameter is related to the mass transfer process.

Pereiro et al. (2012) studied the use of IL in ethanol/water azeotropic system separation and concluded that the most promising IL are those Containing $[\mathrm{OAc}]^{-}$and $[\mathrm{Cl}]^{-}$anions, not being observed any sharp increase in relative volatility when compared to [BF4]. Lei et al. (2009) compared the selectivity in infinite dilution of 24 imidazole-based IL, predicted by UNIFAC model and their results showed that the IL presenting $[\mathrm{BF} 4]^{-}$in its composition have higher selectivity than the others studied and the simulated results show that the IL presenting $[\mathrm{BF} 4]^{-}$in its composition have higher selectivity than the others studied. In addition, the ionic liquid 1-butyl-3methylimidazolium tetrafluoroborate [BMIM] [BF4] presents low viscosity compared to the others IL, which is a desirable characteristic (Zhu et al., 2016). Therefore, based on such favorable physical and thermodynamic properties, [BMIM] [BF4 was the IL selected.

There are countless projects developed with the purpose of breaking the azeotrope involving the feasibility and optimization of processes such as the extractive distillation. The computational simulation has been employed on such projects, with the aim to create a constructive impact on the process economy. The process simulator Aspen Plus ${ }^{\circledR}$ (Aspen Technology, Inc., 2018; APUG, 2000) is software used to facilitate the calculation of physical, chemical and biological processes. It can be used to describe processes involving solids as well as steam and liquid flows. This software is an important tool to the process design (Lan et al., 2018; Matugi, 2013).

Hence, the present research aims to obtain the simulation of anhydrous bioethanol through the extractive distillation, using the process simulator Aspen Plus ${ }^{\circledR}$, pondering which solvent (glycerol or [BMIM][BF4]) is more effective to the anhydrous bioethanol production process.

\section{Problem Formulation}

Anhydrous bioethanol was studied by extractive distillation through Aspen Plus ${ }^{\circledR}$ software simulation. The multicomponent mixture studied is composed of ethanol, water, acetic acid and isoamyl alcohol and it is produced from the fermentation of the broth extracted from sugarcane by yeasts. Glycerol and the ionic liquid 1-butyl3-methylimidazolium tetrafluoroborate [BMIM] [BF4] were the studied solvents in the extractive points. The system actual data were adapted based on (Kuhlmann et al., 2007; Matugi, 2013) works. The Table 1 presents the studied system information. 
The solvent plays an important role in the system. Its characteristics allow changing the activity coefficient in liquid phase and the relative volatility between bioethanol and water, which causes the separation of these compounds, since both of them have similar boiling points: $100^{\circ} \mathrm{C}$ for water and $78^{\circ} \mathrm{C}$ for bioethanol, according to FISPQ-ABNT-NBR 14725 (ABNT, 2009).

Some industrial processes, such as distillation and extraction, put in contact two unbalanced phases, being necessary to understand the thermodynamic criteria that provide the phase equilibrium conditions. The calculations of the thermodynamic conditions for this work are represented by the thermodynamic model Non-Random Two-Liquid (NRTL), because this model presents few errors that can be neglected in equilibrium data prediction (Figueroa, 2011). This model has a wide application for ideal and non-ideal chemical systems of low pressure. The thermodynamic model was chosen for represent of liquid phase and the vapor phase, when considered ideal according to Aspen manual (Ruivo et al., 2010). The system consists of two distillation columns. In the first Column (COLUMN 1), hydrated bioethanol is obtained, while the second Column (COLUMN 2) is intended for extractive distillation to break the azeotrope. The Aspen Plus ${ }^{\circledR}$ simulator provides several columns models for the simulation of distillation and the RadFrac column model is used in this study. This is a rigorous model of multistage distillation, that could be used on simple distillation process, extractive and azeotropic distillation, three-phase distillation and reactive distillation.

The operational parameters used were also initially based on (Matugi, 2013) and they were adjusted in a series of simulations to obtain the parameters that fitted the most system behavior. In Table 2 the operational parameters adjusted for the distillation COLUMN 1 are presented and this column information were after used to feed the COLUMN 2 for the simulation with the solvents Glycerol and [BMIM][BF4] (Table 3).

Table 1: Composition of multicomponent mixture

\begin{tabular}{lll}
\hline Multicomponent mixture & $\begin{array}{l}\text { Mass fraction based on } \\
\text { (Kuhlmann } \text { et al., 2007; Matugi, 2013) }\end{array}$ & Mass fraction (on this work) \\
\hline Water & 0.622519 & 0.876000 \\
Ethanol & 0.376399 & 0.129000 \\
Isoamyl Alcohol & 0.000841 & 0.000740 \\
Propanol & 0.00014561 & ----- \\
Isobutanol & 0.00009411 & ---- \\
Acetic acid & ---- & 0.000920 \\
\hline
\end{tabular}

Table 2: Operation Parameters of Distillation Column (COLUMN 1)

\begin{tabular}{lll}
\hline Specification & $\begin{array}{l}\text { Based on } \\
\text { (Kuhlmann } \text { et al., 2007;Matugi, 2013) }\end{array}$ & Present work \\
\hline Number of equilibrium stages & 7.0 & 15 \\
Isobaric column pressure (bar) & 1.0 & 1.0 \\
Condenser & Total & Total \\
Reboiler & Ketlle & Kettle \\
Reflux ratio & 4.5 & 4.0 \\
Distillate rate $(\mathrm{kg} / \mathrm{h})$ & ---- & 5000 \\
Feeding stage & 3.0 & 12 \\
Feed flow rate $(\mathrm{kg} / \mathrm{h})$ & 28535 & 28535 \\
Feed pressure $(\mathrm{bar})$ & 1.0 & 1.5 \\
Feed temperature $(\mathrm{K})$ & 360 & 360 \\
\hline
\end{tabular}

Table 3: Operation parameters of the Extractive Column (COLUMN 2)

\begin{tabular}{|c|c|c|}
\hline Specification & $\begin{array}{l}\text { Based on } \\
\text { (Lei et al., 2009; Rocha et al., 2016) }\end{array}$ & Present work \\
\hline Feed temperature of the solvent $(\mathrm{K})$ & 353.15 & 360 \\
\hline Feed pressure of the solvent (bar) & 1.0 & 1.5 \\
\hline Condenser & Total & Total \\
\hline Number of stages & 24 & 35 \\
\hline Feed stage of solvent & 4.0 & 3.0 \\
\hline Feed stage of the blend & 12 & 33 \\
\hline Reboiler & Kettle & Kettle \\
\hline Valid phases & Steam-liquid-liquid & Steam-liquid-liquid \\
\hline Convergence & Azeotropic & Azeotropic \\
\hline Key light component & Bioethanol & Bioethanol \\
\hline
\end{tabular}




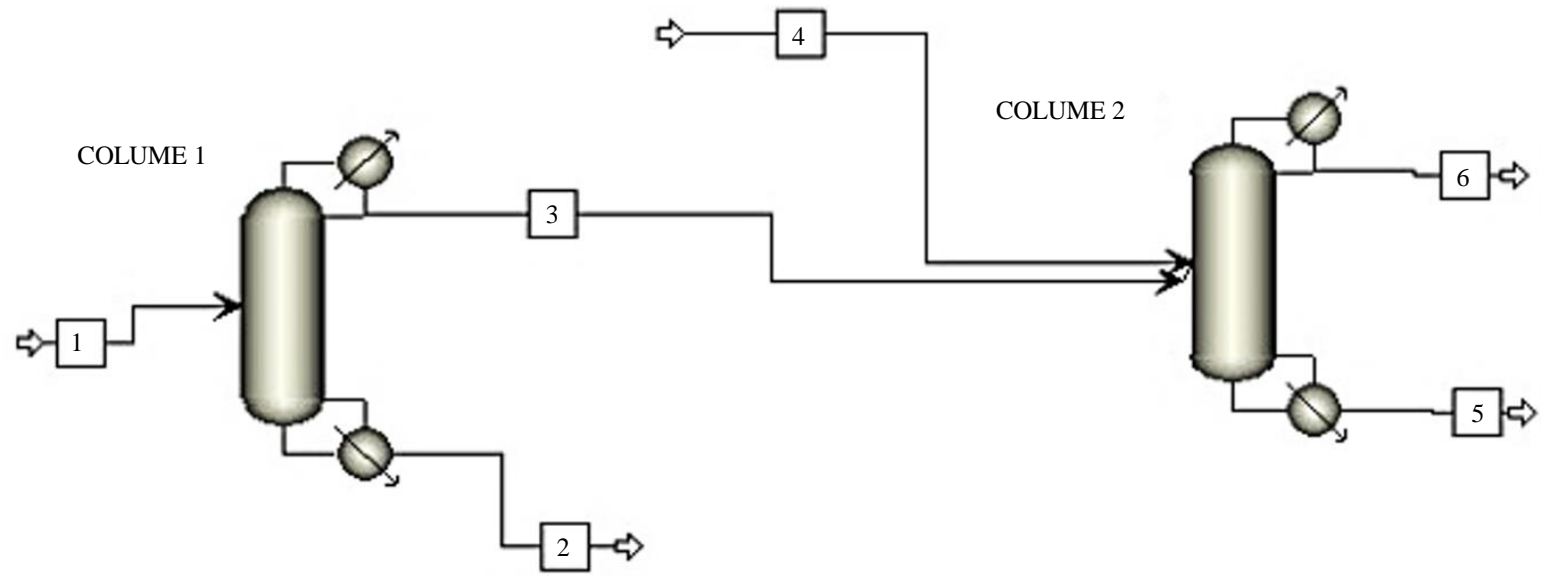

Fig. 1: Representation of the process to obtain anhydrous bioethanol performed on Aspen

In Fig. 1 the schematic representation of the process is shown. For this COLUMN 1, Stage 1 is considered as the top stage of the column and stage 15 the bottom one, that is, downward sequence. The proposed system is composed by the feed flow indicated by stream 1 , which contains the multicomponent mixture (Table 1), with a flow rate of $28535 \mathrm{~kg} / \mathrm{h}$. Because the higher alcohols are heavier alcohols, the less volatile compounds present in the mixture, thus they are withdrawn at the bottom of COLUMN 1, which is represented by stream 2 in the flowchart. In this first column, there is a pre-separation of bioethanol and water present in the mixture. Therefore, most of the bioethanol is extracted from the top, represented by stream 3 and the water leaves as a bottom product of stream 2 .

Hydrated bioethanol obtained in COLUMN1 is sent to the extractive Column (COLUMN2), where there is a solvent feed through stream 4. In this COLUMN2, the solvent is incorporated to hydrated bioethanol, leading to the "break" of the existing azeotrope in the mixture and, by extraction, the solvent drags the water forming a new azeotrope with the solvent/water mixture. The solvent/water mixture is withdrawal from the process at the bottom of the extractive column through stream 5 and the anhydrous bioethanol is obtained at the top, represented by stream 6 .

Similar to the approach adopted for the distillation COLUMN1, several simulations were performed in order to obtain the parameters that suited the most extractive column. Such parameters were initially based on (Lei et al., 2009; Rocha et al., 2016), who described a rigorous simulation for the distillation column. In this column, it was necessary to insert specifications of one of the feed streams. In this case, some parameters were specified for the solvent feed stream, since this component is responsible to change the condition of azeotrope formation and then promote the separation between ethanol and water to obtain anhydrous bioethanol. Such parameters are presented in Table 3 and were kept for the system simulation for both solvents studied (glycerol and [BMIM][BF4]).

As Aspen Plus ${ }^{\circledR}$ software does not have properties related to ionic liquids on it is database, it is necessary to insert them in the simulator. Because of this, the ionic liquid selection was based on the experimental data availability and properties present in literature. The binary parameters of the NRTL model for water/[BMIM][BF4] and for ethanol/[BMIM][BF4] were taken from the literature (Lan et al., 2018; Matugi, 2013). As for the binary parameters of NRTL model for water and ethanol, they are found in the software Aspen Plus's own database. The data used on this simulation for Ionic Liquid [BMIM][BF4] are presented in Table 4 and were added to Aspen Plus ${ }^{\circledR}$ simulator through Pseudocomponent and Dechema modules present in the simulator.

In order to evaluate the viability of the solvents proposed in the present work, standard conditions that ensure a good productivity and a viable process were fixed. The first of them was the purity degree of the product of interest, anhydrous bioethanol, that should be at least of $99.7 \%$ in mass for each solvent tested and in second plan a minimal production of $2764 \mathrm{~kg} / \mathrm{h}$ for the final product was defined. From such conditions, three adjusted variables were fixed - distillate flow rate, reflux ratio and solvent flow rate - which were adjusted until the necessary conditions were met in the proposed system.

From the simulations, the results were analyzed in order to compare the performance of the system using the solvents tested. Thereby, the amount of solvent to be used to obtain the maximum purity values, the influence of the operating conditions, such as the solvent/feed ratio, the reflux ratio, the distillate rate, the solvent feeding position and the number of equilibrium stages were evaluated. Besides, the economic and environment viability of the solvents used were evaluated. 
Table 4: Data entered on Aspen Plus ${ }^{\circledR}$ for the simulation with [BMIM][BF4]

\begin{tabular}{lrl}
\hline Used data & Values & Reference \\
\hline Boiling temperature $(\mathrm{K})$ & 495.2 & Zubir et al. $(2017)$ \\
Density $\left(\mathrm{kg} / \mathrm{m}^{3}\right)$ & 1190.0 & Aspen Technology, Inc. $(2018)$ \\
Molar mass $(\mathrm{g} / \mathrm{mol})$ & 226.0 & Zubir et al. $(2017)$ \\
$\mathrm{g}_{\mathrm{ji}}(\mathrm{J} / \mathrm{mol})$ & 5406.9 & Zubir et al. $(2017)$ \\
$\mathrm{g}_{\mathrm{ji}}(\mathrm{J} / \mathrm{mol})$ & 8301.9 & Zubir et al. $(2017)$ \\
$\alpha$ & 0.3 & Zubir et al. $(2017)$ \\
\hline
\end{tabular}

\section{Results}

The process simulations show that the product of interest can be obtained with the strategies applied. Thereby, the anhydrous bioethanol is recovered according to the purity degree needed and with suitable productivity, using as solvent glycerol and ionic liquid 1-butyl-3methylimidazolium tetra fluoroborate [BMIM][BF4]. The results obtained show the best system adjustment for each solvent used, such as the behavior of these systems when the parameters of the adjusted variables - Distillate Rate, Reflux Ratio and Solvent Flowrate - were changed, which allowed the determination of optimal points of work in each situation.

Table 5 presents the adjusted conditions fitted to the system, with emphasis on anhydrous bioethanol production.

Figure 2 shows the temperature behavior in the first distillation Column (COLUMN 1) and it is observed that the temperature around stage 15 is higher than the others, because this stage is closer to the steam inlet of the reboiler which works at approximately $100^{\circ} \mathrm{C}$. In addition, there is a decrease in temperature, observed between stages 13 and 12 where the mixture is fed into the column at a temperature of around $86^{\circ} \mathrm{C}$, justifying the temperature drop that occurs in these stages. In the intermediate section of the column very few disturbances occur, due to the fact that there is no external interference (such as reflux, feeding, reboiler) which ensures that the temperature remains practically constant between stages 4 and 11, characterizing a plateau in this region. As the reflux in the system occurs near the top of the column, it is noticed that between stages 3 and 1 a sudden drop in the temperature occurs. The presence of the condenser in stage 1 (with a temperature of approximately $86^{\circ} \mathrm{C}$ ) also influences this temperature drop, which explains the sharp variation in the temperature values between these stages. Evaluating the first distillation column of the proposed system, it is noted that it has a performance physically consistent with the expected behavior for this operation.

Based on the simulation, it is possible to observe the dynamic behavior of the distillation column, which the stage 1 is considered as the top stage of the column for this system and the stage 15 the bottom, that is, downward sequence.

Comparing the mass fraction profile on liquid and steam phases, Fig. 3, it is observed a normal behavior for both fractions, wherein the bottom product is richer in water than the top product of the distillation column. Isoamyl alcohol and acetic acid also exit at the bottom of the column because they are heavy alcohols. The liquid fractions of these components are concentrated at the bottom of the column, where they are withdrawn as a bottom product, which shows that distillation is effectively running. At the bottom of the column (stage 15), it can be noted that the net fraction of water has its highest value and the net fraction of ethanol has the lowest value. Thus, it can be observed that the distillation process occurs effectively, in which it is expected that a water-rich and ethanol-poor bottom product be obtained.

Between stages 12 and 14 it is possible to notice a slight disturbance in the liquid fractions (drop in water fraction and increase in ethanol fraction), due to the feeding flow that occurs in stage 13. Between stages 3 and 1, there are sudden changes in the liquid fractions for both ethanol and water, because it is at the top of the column that component separation actually occurs, which is consistent with the physical process expected for the column. At the top of the column there is a product fully condensed, ethanol-rich with a few other components.

The amount of water coming out on top along with bioethanol represents an azeotropic mixture (ethanolwater) under the studied operating conditions. According to (Matugi, 2013), for the composition found, about $95.6 \%$ in mass of ethanol, the liquid and steam phase compositions of the ethanol-water system become equal, which characterizes the azeotropic phenomenon between the components.

Moreover, between stages 12 and 14, for both ethanol and water, it is noted a behavior of steam fraction similar to the behavior of liquid fractions. However, it is clear that the steam phase has a higher sensitivity to the stream that is fed at this stage. This is because the steam phase is more concentrated near the reboiler, where the mixture (stage 13) is also fed at a temperature lower than the temperature inside the column. In this case, the steam phase eventually condenses, causing a sharp drop in this section of the column.

By analyzing the extractive Column (COLUMN 2) it is possible to compare the temperature behavior of the two solvents in question, Fig. 4. It is seen that along the column plateau section (stage 31 to stage 13) there are no considerable variations in the column temperature in simulations with both solvents. However, it can be seen that in simulations with glycerol, the working temperature is 
higher, about $95^{\circ} \mathrm{C}$, whereas for the process with [BMIM] [BF4], this temperature is about $80^{\circ} \mathrm{C}$, which is close to the azeotrope temperature of the ethanol/water mixture $\left(78.2^{\circ} \mathrm{C}\right)$. This indicates that using glycerol as a solvent for breaking the azeotrope is easier when compared to the IL, which corroborates the results obtained in the simulations, in which a smaller amount of glycerol is consumed as solvent to perform the extraction process.

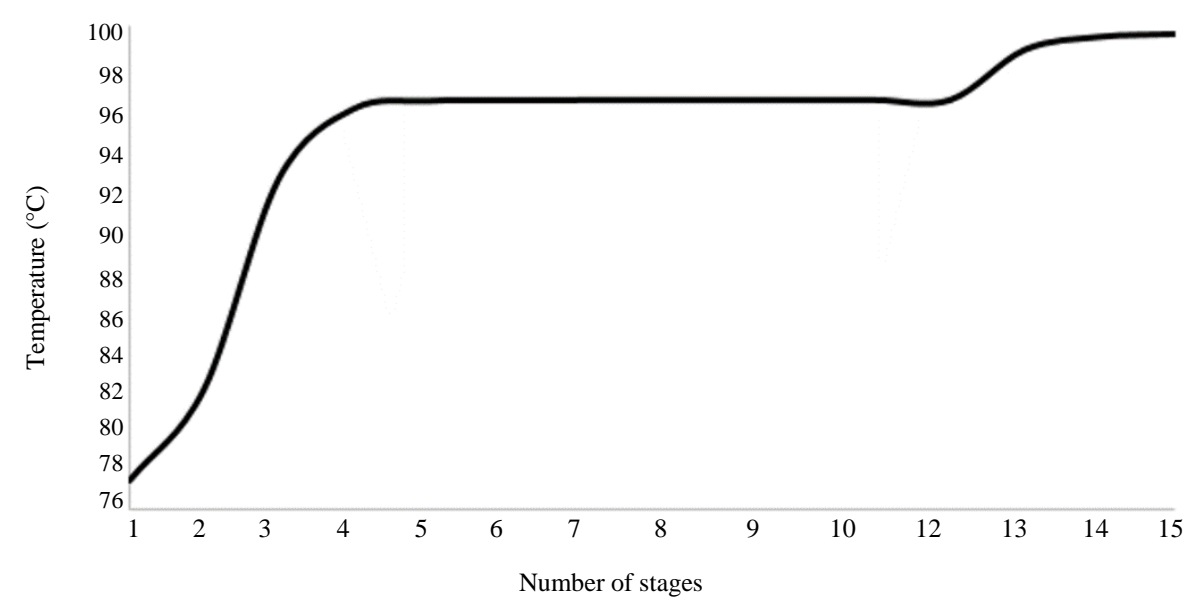

Fig. 2: Temperature behavior as a function of distillation column stages (COLUMN 1)
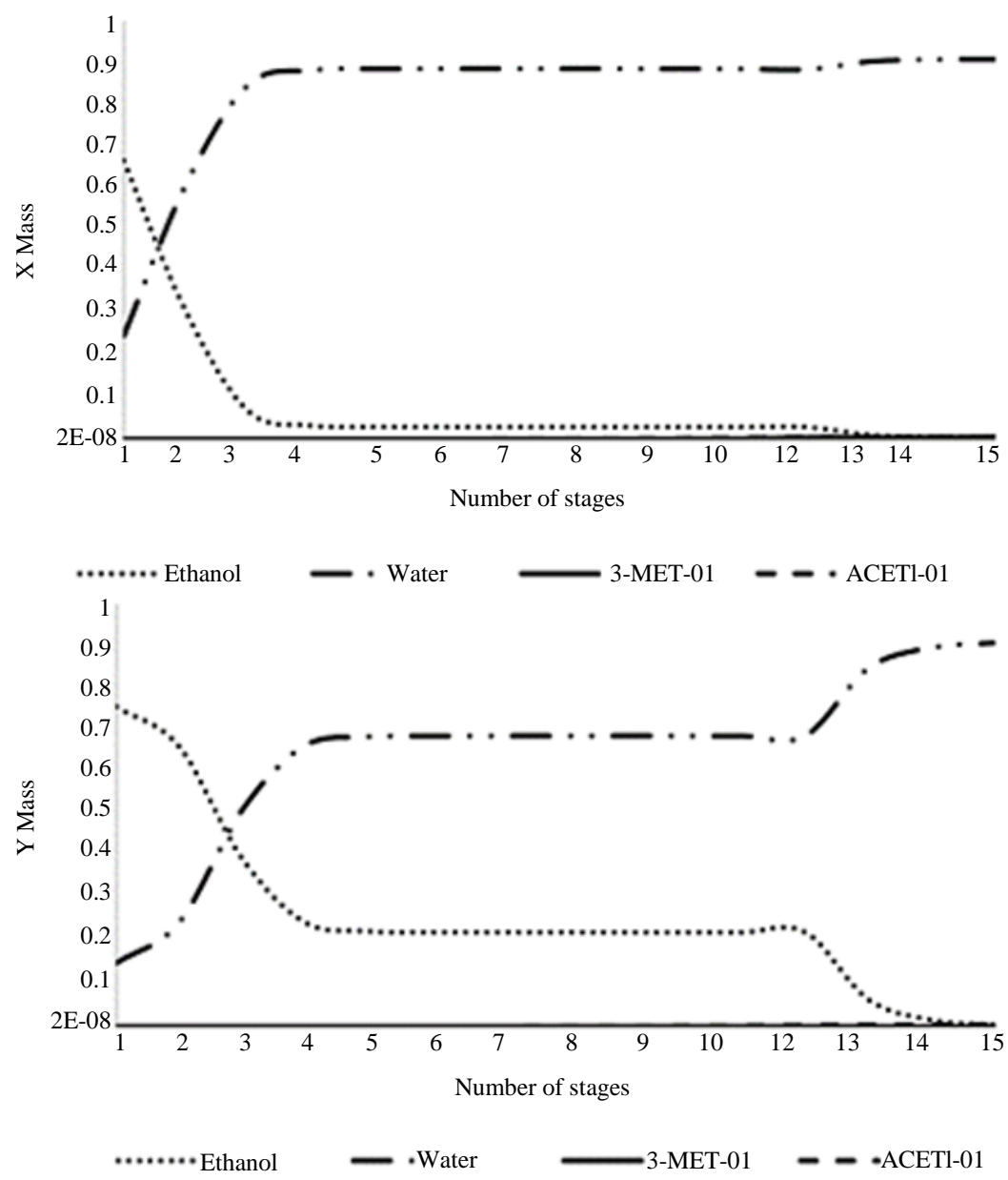

Fig. 3: Mass fraction profile on liquid phase (a) and steam (b) through the first distillation column stages 


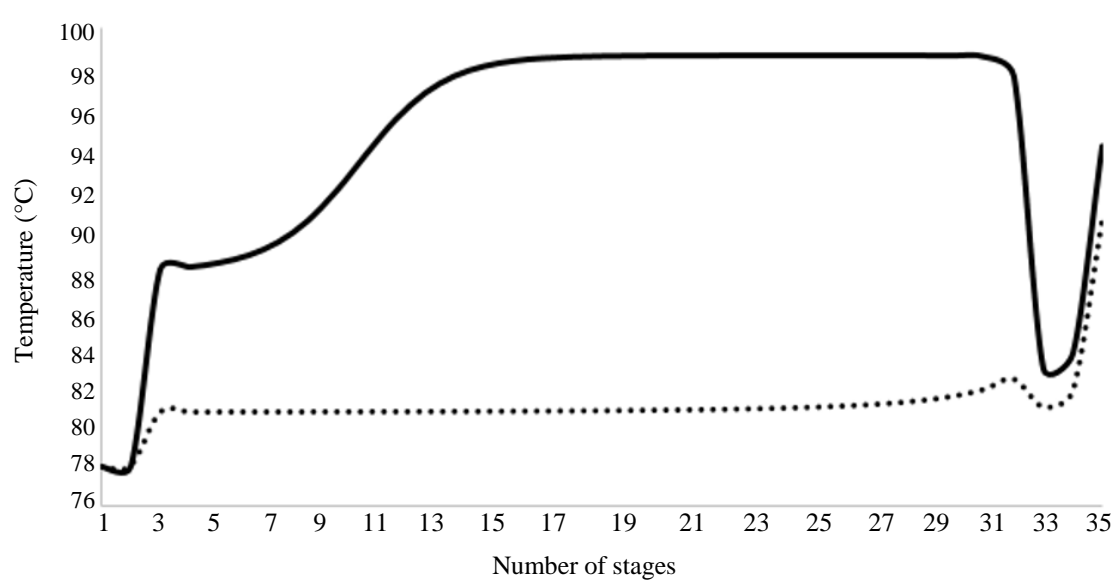

a)
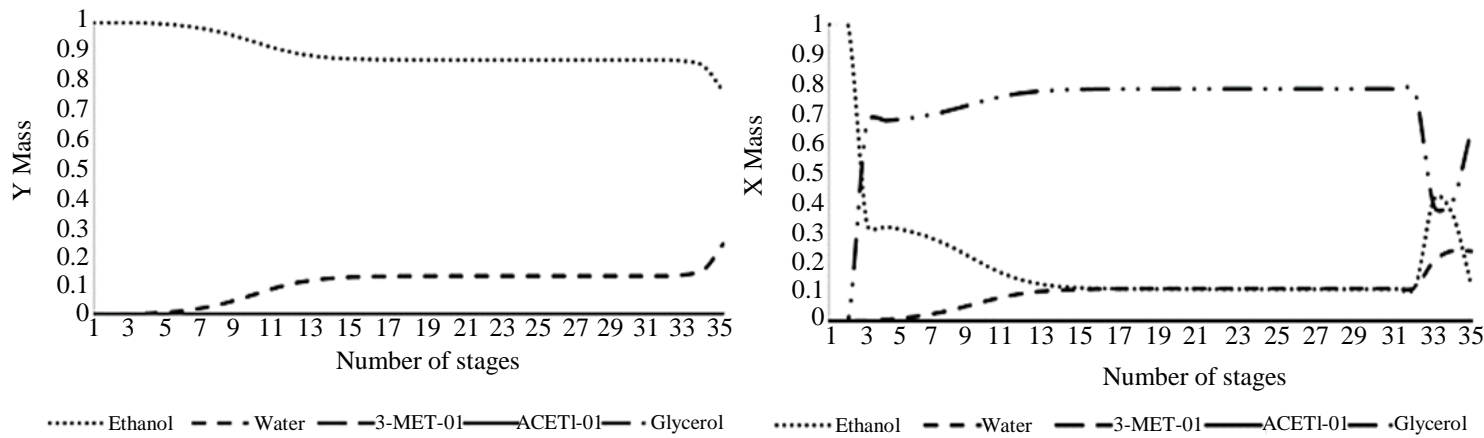

b)
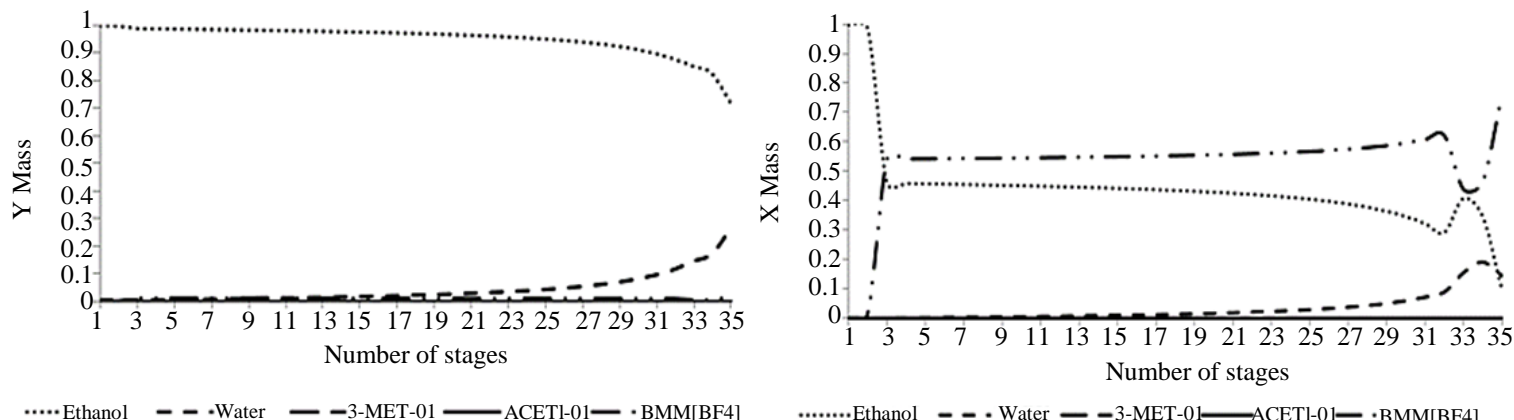

Fig. 5: Concentration profiles on extractive column (a) steam phase and (b) liquid phase for both solvents

Table 5: Specific parameters of the extractive Column (COLUMN 2) for each solvent

\begin{tabular}{lrr}
\hline Specifications & Glycerol & [BMIM][BF4] \\
\hline Distillate rate $(\mathrm{kg} / \mathrm{h})$ & 3000.0 & 1750.0 \\
Reflux ratio & 0.6 & 2.2 \\
Solvent flow rate $(\mathrm{kg} / \mathrm{h})$ & 3750.0 & 7000.0 \\
\hline
\end{tabular}

With the simulations, we can see that the temperature sensibility is bigger for the process with glycerol, which is noted between stages 5 and 11, given the abrupt decline of the temperature followed by a peak. The decrease comes from the reflux feed in the column which enters with a lower temperature. The peak, expressed in stage 3, is resultant of the feed stream of ethanol-water mixture, fed in a temperature of $79.3^{\circ} \mathrm{C}$. On the other hand, for the ionic liquid column, the reflux ratio does not impact significantly the temperature, since the column operates 
at approximately $80^{\circ} \mathrm{C}$ and the reflux temperature is $78^{\circ} \mathrm{C}$. Furthermore, the behavior of both solvents in the column is equivalent, in stage 33 both solvents are fed and they get inside the extractive column with the same temperature and after the interferences of each system the temperatures are equivalent.

According to Fig. 5a, it is noted that the steam fraction of the solvents is present in low concentrations due to its low relative volatility. Moreover, it can be seen for both Fig. 5a and 5b that when solvent feed (stage 3) occurs, there is an increase in solvent concentration and consequently a sharp decline in ethanol concentration. As the stages move forward, the solvent concentration decreases as a result of the separation process. As a result, the system temperature increases and thus the ethanolwater azeotrope separation begins. It is noteworthy that, in simulations with glycerol, the liquid fraction of ethanol remains approximately constant until stage 13 , which is where the reflux feeding occurs. From this stage, it is evident the separation of the azeotrope, which is increased from the stage 3 , where the solvent feed and the azeotrope break actually occur. This fact is not noticed in the simulation with [BMIM] [BF4], since for this solvent the reflux feeding does not cause any significant interference, so the azeotrope separation is only evidenced from stage 3 .

Hence, the top ethanol composition is increased (up to $99.7 \%$ in mass approximately) and the water and solvent composition decreases, as expected. As bioethanol is the product of interest, the amount of water should be minimal, making it anhydrous bioethanol, according to the legislation. Finally, the bottom product has a high concentration of solvent and water and, therefore, minimal concentration of ethanol.

According to Fig. 6a, it can be noticed that the solvent flow rate is directly related to the anhydrous ethanol concentration at the top of the extractive column. As the solvent flow rate increases, there is also an increase in the purity degree of bioethanol present in the distillate stream, which is observed for both the process with glycerol as with ionic liquid.

However, when the processes are compared, it can be observed that the concentration of anhydrous bioethanol at the top of the column responds more sharply to the variations on the flow rate in the operation with glycerol, which makes the product reach a purity degree of $100 \%$ of bioethanol. Thus, for the operation with ionic liquid, the system requires bigger flow rates of this solvent to reach the same values of anhydrous bioethanol concentration when compared to the process with glycerol.

In Fig. $6 \mathrm{~b}$ and $6 \mathrm{c}$, we can observe that as the amount of solvent fed to the extractive column raises, the follow behavior is observed: The flow rate of water tends to zero while the flow rate of bioethanol tends to its maximum value. In comparison with the Fig. 6a, we conclude that such behavior is expected, considering that the mass fraction of anhydrous bioethanol obtained is related to the concentrations of water and bioethanol present at the top of the extractive column. Thus, maximum amounts of ethanol and minimal amounts of water are expected for an efficient separation process in the distillation process.

According with Fig. 7a, as the reflux ratio is increased; the mass concentration of anhydrous bioethanol at the top of the extractive column is also increased. In the system fed with glycerol, the purity of the product presented an initial behavior almost linear until the reflux ratio reached 0.6 . For reflux ratio higher than 0.8 , the mass concentration was of $100 \%$ of anhydrous bioethanol on the distillate product. As for the operation with ionic liquid, the product reached 0.9950 of purity for a reflux ratio of 1.5 and from this value the mass concentration of bioethanol is stabilized in 0.9961 . Therefore, for lower reflux ratio, less bioethanol returns to the extractive column and consequently the purity of anhydrous bioethanol is smaller if compared with bigger reflux ratios.

Figure $7 \mathrm{~b}$ and $7 \mathrm{c}$ shows that as the reflux ratio is increased, the bioethanol flow rate tends to its maximum value and the water flow rate tends to zero, making the mass fraction of bioethanol at the top of the extractive column higher. For a reflux ratio equals to 1.0 , the flow rate of bioethanol and water, operating with glycerol, is 3000.078 and $0.00018 \mathrm{~kg} / \mathrm{h}$, respectively. As for the ionic liquid, such flow rates present the following values: 2712.37 and 60.97 $\mathrm{kg} / \mathrm{h}$, respectively. It can be observed that the process with glycerol reaches bigger concentration of anhydrous bioethanol for a same reflux ratio, when compared to the process with ionic liquid, being, therefore, the process with glycerol more sensible to variations in such parameter.

Figure 8a shows that the increase on the distillate rate reduces the mass concentration of ethanol in the distillate, differently from the behavior showed by the solvent flow rate and the reflux ratio. For the distillate rate of $1000 \mathrm{~kg} / \mathrm{h}$, the purity of anhydrous bioethanol presents a value of 1.0 when the system was fed with glycerol, in other words, the distillate is composed only by anhydrous bioethanol. However, for the same distillate rate, when ionic liquid is used, the purity presents the value of 0.9993 .

It can be observed that the concentration of bioethanol at the top, for both solvents, remains almost constant for the distillate rate values from 1000 to $2000 \mathrm{~kg} / \mathrm{h}$. For distillate rate of $3000 \mathrm{~kg} / \mathrm{h}$ and forward, there is a sharp drop on the anhydrous bioethanol purity. Besides, the process with IL is more sensible to variations on the distillate rate, thus, for the same purity degree needed for glycerol, a lower distillate rate is required. Therefore, to obtain anhydrous bioethanol with the concentration of $99.7 \%$ in mass, it should be considered the range of 1000 to $3000 \mathrm{~kg} / \mathrm{h}$ for glycerol and 1000 to $2000 \mathrm{~kg} / \mathrm{h}$ for the ionic liquid. 
a)

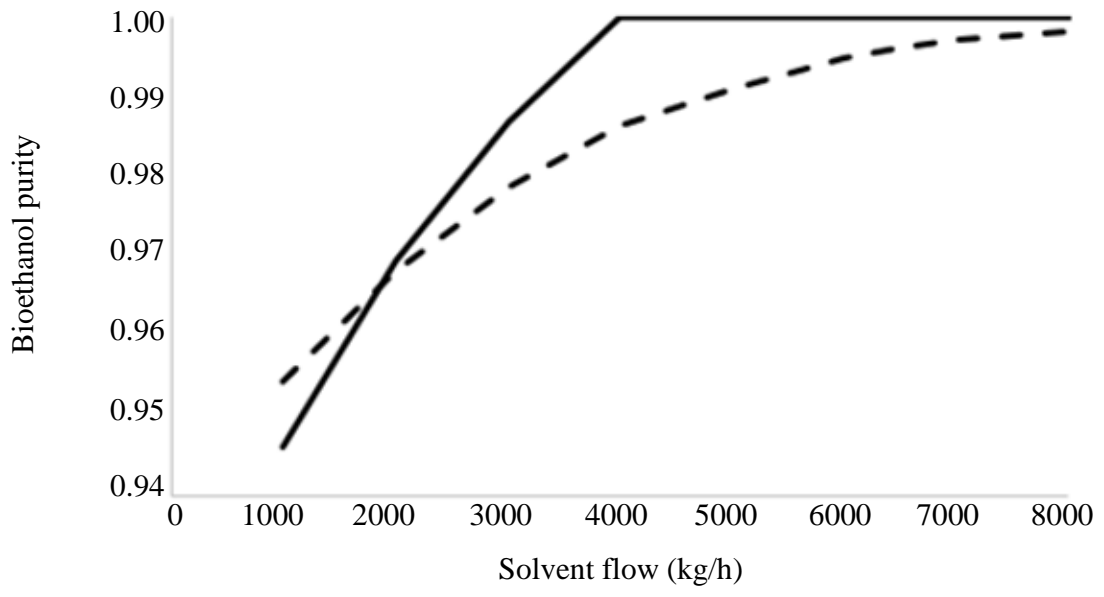

b)

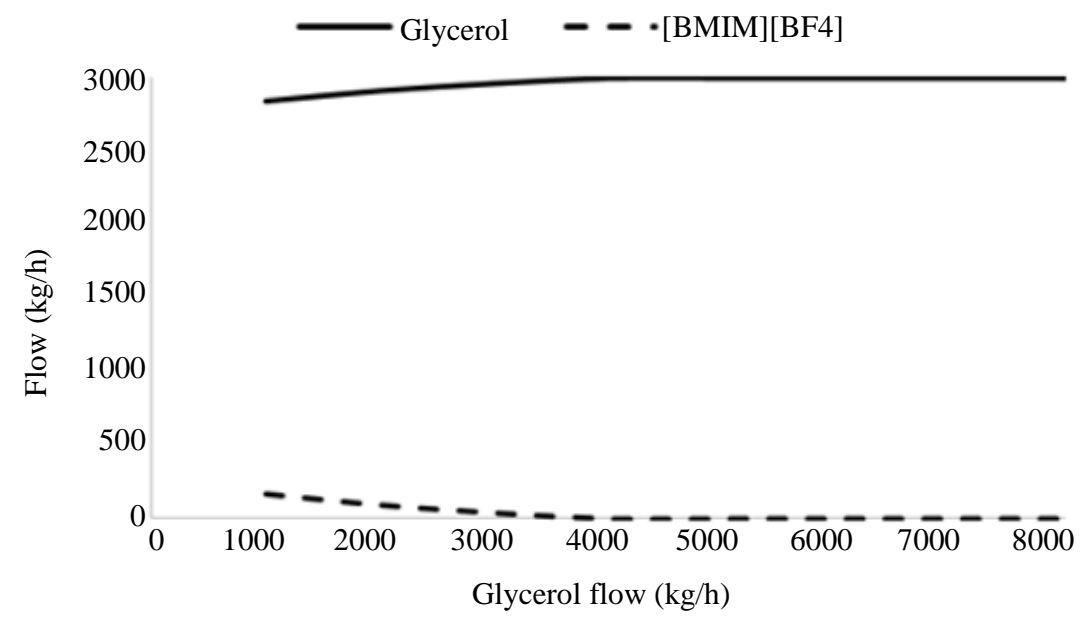

c)

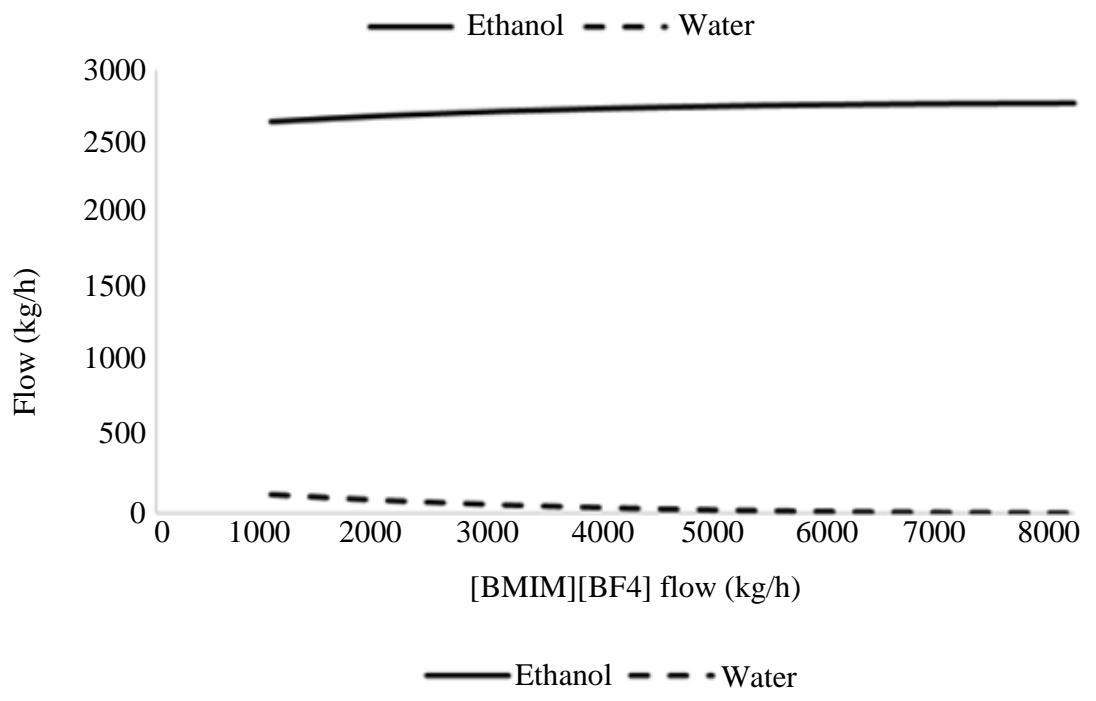

Fig. 6: (a) Variation of the mass flow of glycerol and [BMM][BF4] solvents according to the purity of bioethanol at the top of the extractive column. Bioethanol and water flow profile as a function of the variation in the supply of solvents (b) glycerol and (c) $[\mathrm{BMIM}][\mathrm{BF} 4]$, according to the data presented in Table 5 
a)
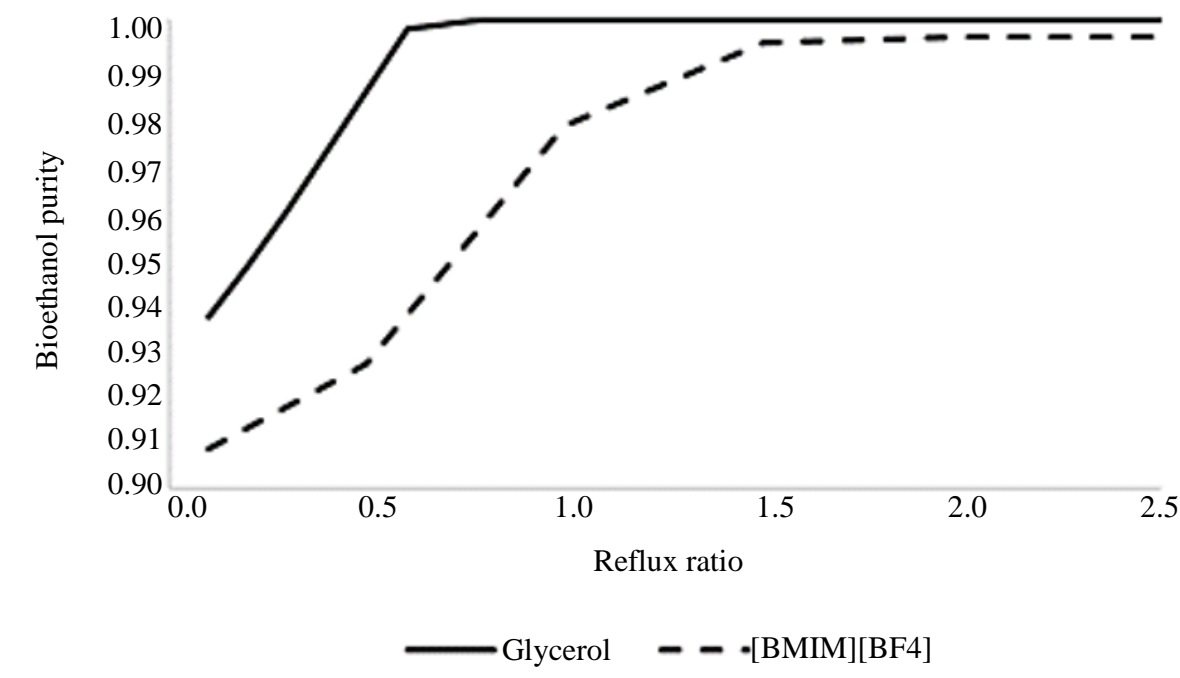

b)

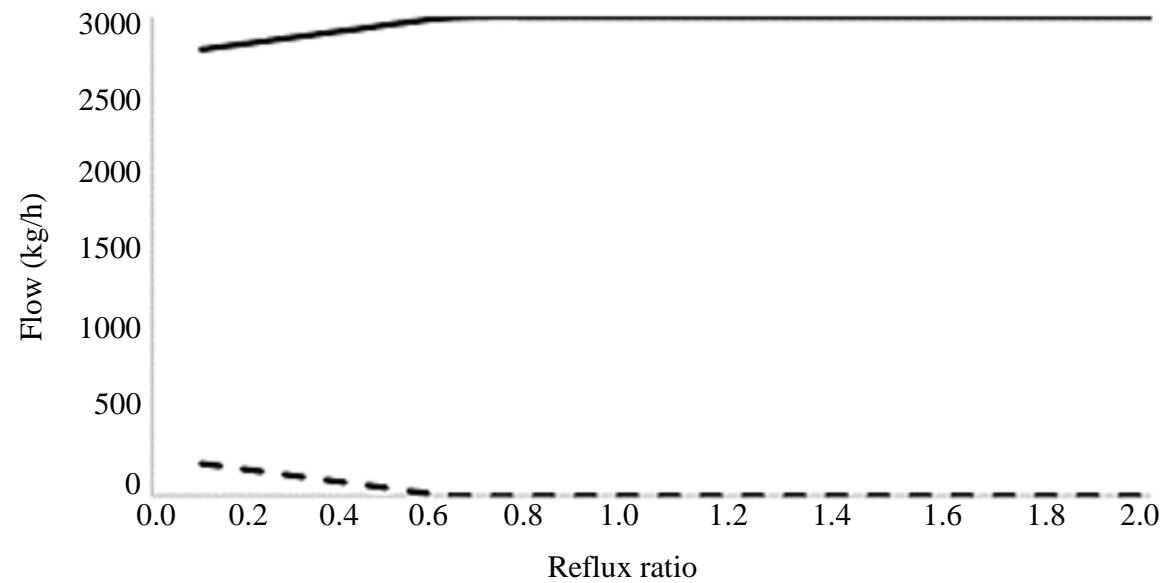

c)

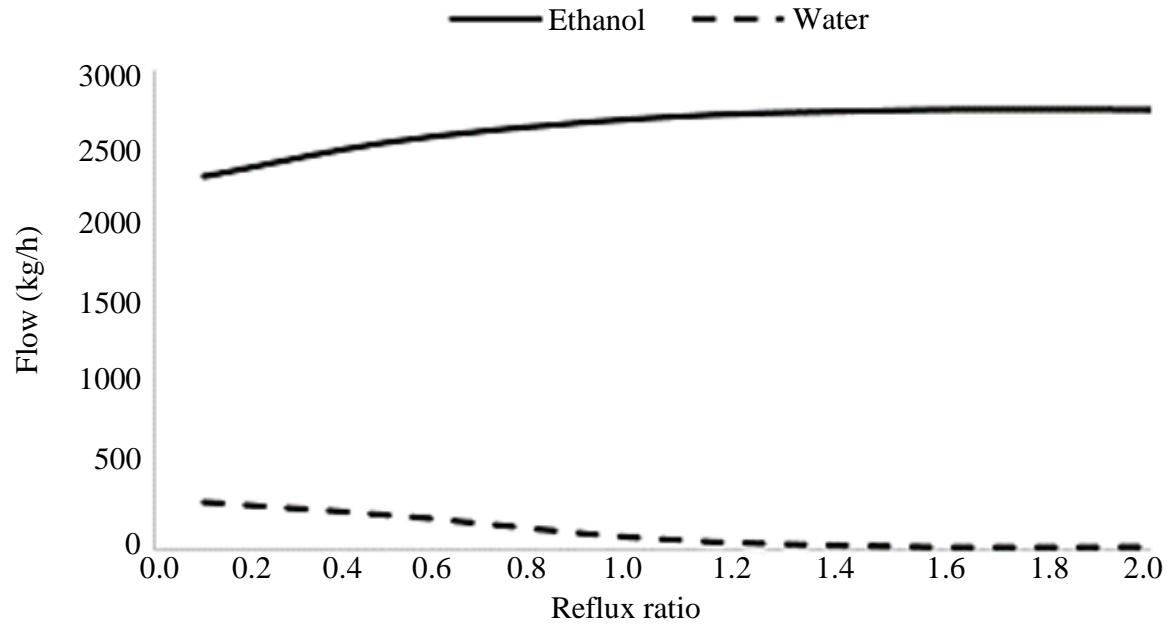

Ethanol - - Water

Fig. 7: (a) Variation of the reflux ratio in the systems fed with glycerol and [BMM][BF4] solvents, due to the purity at the top of the extractive column. Bioethanol and water flow profile as a function of the variation in the reflux ratio for the systems fed with (b) glycerol and (c) $[\mathrm{BMM}][\mathrm{BF} 4]$, according to the data presented in Table 5 
a)

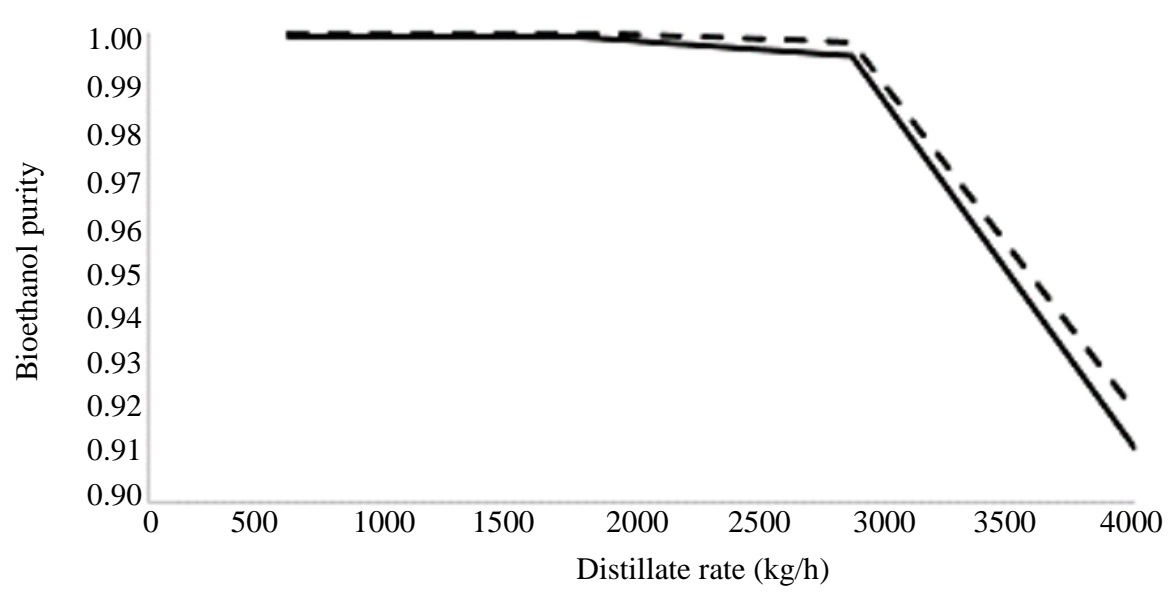

- - Glycerol $\longrightarrow[\mathrm{BMIM}][\mathrm{BF} 4]$

b)

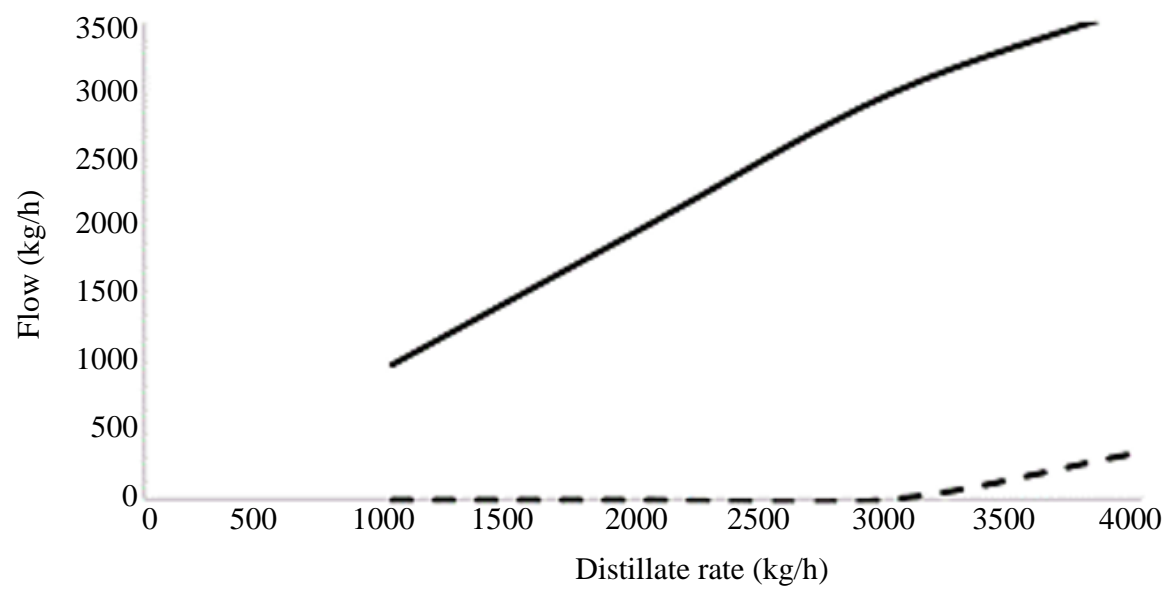

c)

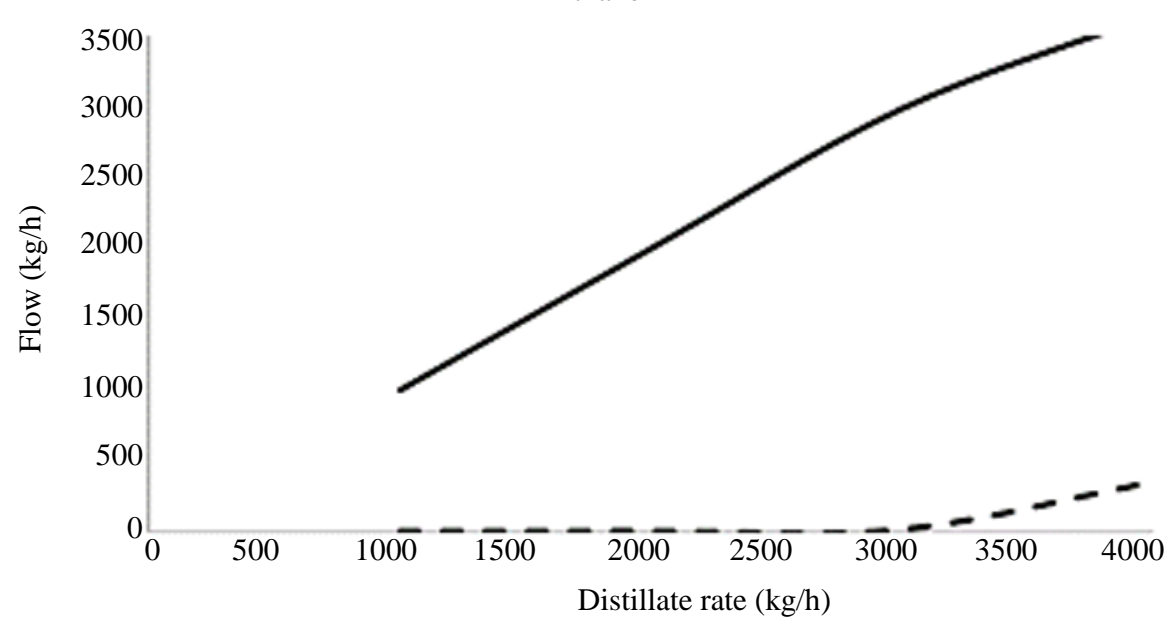

- Ethanol - - Water

Fig. 8: (a) Variation of the distillate rate in the systems fed with glycerol and [BMM][BF4] solvents, due to the purity of bioethanol at the top of the extractive column. Bioethanol and water flow profile as a function of the variation in the rate of distillation, for the systems fed with b) glycerol and c) [BMM][BF4], according to the data presented in Table 5 
Table 6: Comparison of expenditures and bioethanol productivity for glycerol and [BMIM][BF4] solvents

\begin{tabular}{lccl}
\hline & With glycerol & With [BMIM][BF4] & Unit \\
\hline Commercial price & 0.20 & 1.00 & $\mathrm{U} \$ / \mathrm{kg}$ \\
Expenditure consumption & 750.00 & 7000.00 & $\mathrm{U} \$ / \mathrm{h}$ \\
Ethanol production (molar) & 65.00 & 60.09 & $\mathrm{kmol} / \mathrm{h}$ \\
Ethanol production (mass) & 2994.64 & 2768.21 & $\mathrm{~kg} / \mathrm{h}$ \\
Year production (ton) & 25873.71 & 23917.32 & Ton/year \\
\hline
\end{tabular}

*Considering Ethanol commercial price: $0.4 \mathrm{U} \$ / \mathrm{kg}$

According to the Fig. $8 \mathrm{~b}$ and $8 \mathrm{c}$, with the raise in the distillate rate, the flow rates of bioethanol and water also raise, however the variation of the water flow is little for values of distillate rate lower than $3000 \mathrm{~kg} / \mathrm{h}$, causing the decrease of bioethanol purity. Therefore, for glycerol, the ethanol flow rate is $2994.50 \mathrm{~kg} / \mathrm{h}$ and the water flow rate is equal to $5.55 \mathrm{~kg} / \mathrm{h}$. For the ionic liquid, the ethanol flow rate is $2985.15 \mathrm{~kg} / \mathrm{h}$ and the water flow rate is $13.85 \mathrm{~kg} / \mathrm{h}$. Thus, it can be observed that, for the same distillate rate, the process with glycerol presents the bigger mass concentration of bioethanol, when compared to the process with the ionic liquid.

With a growing demand for more sustainable production processes, the production of bioethanol from renewable sources and which favors the sustainability has increasingly been studied. Some works as (Navarrete-Contreras et al., 2014; Lan et al., 2018), seek the development of separation processes energetically efficient for a production economically viable of bioethanol and they use as an alternative the solvent glycerol. In this present work, the energetic and economic demands as well as the environmental impact of the production process of anhydrous bioethanol using the proposed solvents were evaluated. The Table 6 presents a summary about production of anhydrous bioethanol, for the processes using each of the studied solvent.

Based on the results described on Table 6, it is noticeable that when both solvents evaluated in this study are compared to each other, there is a higher spend for the [BMIM][BF4], around $89 \%$ more, if compared to the solvent for glycerol. As reported before, the ionic liquid consumption was bigger than the glycerol, approximately 1.9 times more. Such result impacts significantly on the production cost of anhydrous bioethanol, being this decisive parameter on process viability.

The ionic liquid still has a high commercial value, because it is a synthetic product and still little explored in the industry, what makes its unfeasible use on the productive process of anhydrous bioethanol. In contrast, the simulation proposed using glycerol as solvent showed satisfying results for solvent consumption and productivity, besides having a low commercial value. A lower consumption of solvent associated to low prices effectively collaborates for the plant sustainability and positive billing in the process.

Another contributing factor for the productive process evaluation proposed for each solvent is the amount of heat required. The process with ionic liquid needs a higher amount of heat than that with glycerol. This fact is deeply connected with the amount of solvent needed in each simulation, since the greater the consumption the more energy is required to perform the operation. Therefore, it was observed that [BMIM][BF4] demands a bigger energetic spent for the plant when it is used as solvent.

Finally, according to the results, it can also be evaluated the amount of anhydrous bioethanol produced from the process performed with each solvent. The process where glycerol was used as solvent also showed to be a better option at this point when compared to the process using [BMIM][BF4], since it resulted in a production of nearly $8 \%$ more of bioethanol. Hence, as the extractive column feed is the same for both solvents, the process with glycerol demonstrated a better productivity, which makes it more viable when compared to the process with Ionic Liquid.

Navarrete-Contreras et al. (2014) showed through experimental results that glycerol may be considered as good solvent to break azeotrope in mixtures of ethanol and water in industrial process, ahead of ionic liquids and ethylene glycol. Jardim et al. (2014) also presented advantages of the glycerol used as solvent on dehydration process of bioethanol by extractive distillation when compared to ethylene glycol, since glycerol has a low toxicity, presents high separation efficiency and its availability is growing on the market because it is a by-product of biofuel production without an appropriate fate. This solvent showed to be efficient on anhydrous bioethanol production with great potential for industrial application.

\section{Discussion}

The present work focused on anhydrous bioethanol simulation process by extractive distillation using glycerol and ionic liquid [BMIM] [BF4] as solvents. The thermodynamic model NRTL was used for the calculations performed in this study. The entire distillation process, both conventional and extractive, was conducted in the software Aspen Plus. The work approach involves process simulations, comparatively showing the separation performance of the ethanol/water mixture using each solvent. Then, an economic feasibility analysis of the process was performed. The simulations performed 
in this study to obtain anhydrous bioethanol using glycerol and 1-butyl-3-methylimidazolium-tetrafluoroboratono as solvents, showed that the processes with solvents allowed reaching the required purity of $99.7 \%$ in mass of bioethanol and the productivity of $2764 \mathrm{~kg} / \mathrm{h}$ of anhydrous bioethanol at the end of the operation.

From the results obtained, some comparative advantages regarding the use of glycerol over ionic liquid are highlighted. Initially, the environmental context is brought to light, in which, with the use of glycerol, the negative impacts caused by its accumulation and improper disposal would be minimized, ensuring the sustainability of the process. On the other hand, ionic liquid can be an alternative to reduce environmental pollution, preventing the emission of volatile organic components to the environment, but it is a synthetic product which makes its commercial value high. Moreover, in regards of the production process, it is possible to notice that the conventional distillation column behaves similarly for both solvents, which implies in a more detailed study in the extractive column. Thus, the result obtained in the extractive column in relation to the reflux ratio of glycerol was 0.6 , in contrast to the reflux ratio of 1-butyl-3-methylimidazolium tetra fluoroborate which was 2.2. The flow rate of glycerol fed is $46.4 \%$ lower compared to the solvent flow rate for the ionic liquid and it requires a thermal load of $1.75 \%$ lower than the load consumed by the ionic liquid. In addition, [BMIM] [BF4] has an expenditure of approximately $89 \%$ more and glycerol has an approximate production of $8 \%$ more of anhydrous bioethanol. Therefore, based on the results obtained, the most viable solvent for this process, both economically and environmentally, was the glycerol.

\section{Acknowledgment}

The authors of this paper would like to thank UFVJM and ICT/UFVJM for theall the support.

\section{Author's Contributions}

José Izaquiel Santos da Silva: Make considerable contributions to conception and design, and acquisition of data, and Analysis and interpretation of data. Coordinated the mouse work. Designed the research plan and organized the study. Contributed in drafting the article or reviewing it critically for significant intellectual content; and give final approval of the version to be submitted and any revised version.

Lílian da Silva Félix, Mariana Martins Vieira and Victória Caroline Veloso Meireles: Make considerable contributions to conception and design, and acquisition of data, and Analysis and interpretation of data. Contribute in drafting the article or reviewing it critically for significant intellectual content.
Edilailsa Januário de Melo: Make considerable contributions to conception and design, and acquisition of data, and Analysis and interpretation of data.

Rogério Alexandre Alves de Melo: Make considerable contributions to conception and design, and acquisition of data, and Analysis and interpretation of data, and contributed to the writing of the manuscript

\section{Ethics}

This article is original and contains unpublished material. The authors have read and approved this manuscript and no ethical issues are involved.

\section{References}

ABNT. (2009). Chemicals - Safety, health and environmental information; Part 1: Terminology. ABNT - Brazilian Association of Technical Standards. https://www.abntcatalogo.com.br/norma.aspx?ID=5 7670

ANP. (2011). ANP - Brazilian National Agency of Petroleum, Natural Gas and Biofuels. ANP Resolutions (2011).

http://legislacao.anp.gov.br//?path=legislacaoanp/resol-anp\&id=1671\&sub=102

APUG. (2000). Aspen Technology, Aspen Plus User Guide. Version 10.2.

(https://web.ist.utl.pt/ist11038/acad/Aspen/AspUs erGuide10.pdf).

Aspen Technology, Inc. (2018). Process Simulation for Chemicals. https://www.aspentech.com/en//media/aspentech/home/resources/brochure/pdfs/at03992-bro-aspen-plus.pdf

Figueroa, J. E. J. (2011). Analysis and optimization of anhydrous ethanol production using ionic liquids (the original text is in Portuguese). Dissertation (Master in Chemical Engineering). FEQ/UNICAMP, Brazil. http://repositorio.unicamp.br/jspui/handle/REPOSIP /266843

Jardim, H. A., Moura, L. F., \& Cruz, A. J. (2014). Anhydro Ethanol Production Through Distillation Extractive Using Glycerol, In: Proceedings of the 20th Brazilian Chemical Engineering Congress COBEQ 2014 [= Blucher Chemical Engineering Proceedings.

https://proceedings.science/cobeq/cobeq2014/papers/producao-de-etanol-anidro-viadestilacao-extrativa-utilizando-glicerol

Kuhlmann, E., Himmler, S., Giebelhaus, H., \& Wasserscheid, P. (2007). Imidazolium dialkylphosphates-a class of versatile, halogenfree and hydrolytically stable ionic liquids. Green Chemistry, 9(3), 233-242.

https://pubs.rsc.org/en/content/articlelanding/200 7/gc/b611974c/unauth 
Kulajanpeng, K., Suriyapraphadilok, U., \& Gani, R. (2016). Systematic screening methodology and energy efficient design of ionic liquid-based separation processes. Journal of Cleaner Production, 111, 93-107. https://doi.org/10.1016/j.jclepro.2015.07.052

Lan, W., Chen, G., Zhu, X., Wang, X., Liu, C., \& Xu, B. (2018). Biomass gasification-gas turbine combustion for power generation system model based on ASPEN PLUS. Science of the Total Environment, 628, 1278-1286. https://doi.org/10.1016/j.scitotenv.2018.02.159

Lei, Z., Zhang, J., Li, Q., \& Chen, B. (2009). UNIFAC model for ionic liquids. Industrial \& Engineering Chemistry Research, 48(5), 2697-2704. https://doi.org/10.1021/ie801496e

Masson, I. D. S., Costa, G. H. G., Roviero, J. P., de Freita, L. A., Mutton, M. A., \& Mutton, M. J. R. (2015). Bioethanol production from sweet sorghum broth and sugar cane fermentation. Ciência Rural, 45(9), 1695-1700. https://doi.org/10.1590/0103-8478cr20130549

Matugi, K. (2013). Anhydrous ethanol production by extractive distillation using saline and glycerol solutions (the original text is in Portuguese). Dissertation (Master in Exact and Earth Sciences). Federal University of São Carlos, Brazil. https://repositorio.ufscar.br/handle/ufscar/4111

Navarrete-Contreras, S., Sánchez-Ibarra, M., BarrosoMuñoz, F. O., Hernández, S., \& Castro-Montoya, A. J. (2014). Use of glycerol as entrainer in the dehydration of bioethanol using extractive batch distillation: Simulation and experimental studies. Chemical Engineering and Processing: Process Intensification, 77, 38-41. https://doi.org/10.1016/j.cep.2014.01.003

Pereiro, A. B., Araújo, J. M. M., Esperança, J. M. S. S., Marrucho, I. M., \& Rebelo, L. P. N. (2012). Ionic liquids in separations of azeotropic systems-A review. The Journal of Chemical Thermodynamics, 46, 2-28. https://doi.org/10.1016/j.jct.2011.05.026

Pieczyńska, A., Ofiarska, A., Borzyszkowska, A. F., Białk-Bielińska, A., Stepnowski, P., Stolte, S., \&Siedlecka, E. M. (2015). A comparative study of electrochemical degradation of imidazolium and pyridinium ionic liquids: a reaction pathway and ecotoxicity evaluation. Separation and Purification Technology, 156, 522-534. https://doi.org/10.1016/j.seppur.2015.10.045

Rocha, L. B., Moreira, W. M., \& Lima, O. C. M. (2016). Rigorous Simulation of Aspen Plus ${ }^{\circledR}$ Distillation Columns for the Production of Hydrated Ethanol and Anhydrous Ethanol. Proceedings of the III Fateb Research Meeting, 2, 491-511 (2016). http://fatebtb.edu.br/arquivos-ftp/encontro-depesquisa2017/III\%20Encontro\%20de\%20PesquisaVol\%20II \%20-\%20Eng\%20Quimica.pdf
Ruivo, R., Couto, R., \& Simões, P. C. (2010). Screening of ionic liquids as promising separation agents of oil mixtures for application in membranes. Separation and Purification Technology, 76(1), 84-88. https://doi.org/10.1016/j.seppur.2010.09.032

Souza, W. L., Silva, C. S., Meleiro, L. A., \& Mendes, M. F. (2013). Vapor-liquidequilibriumofthe (water+ ethanol+ glycerol) system: Experimental andmodelling data at normal pressure. The Journalof Chemical Thermodynamics, 67, 106-111. https://doi.org/10.1016/j.jct.2013.07.012

Teng, W. K., Ngoh, G. C., Yusoff, R., \&Aroua, M. K. (2016). Microwave-assisted transesterification of industrial grade crude glycerol for the production of glycerol carbonate. Chemical Engineering Journal, 284, 469-477. https://doi.org/10.1016/j.cej.2015.08.108

Zanardi, S. M., \& Junior, C. F. E. (2016). Technology and perspective of ethanol production in Brazil. Revista Liberato, 17(27), 01-118. https://doi.org/10.31514/rliberato.2016v17n27.p20.

Zarca, G., Urtiaga, A., Ortiz, I., Cañizares, P., \& Rodrigo, M. A. (2015). Carbon monoxide reactive separation with basic 1-hexyl-3-methylimidazolium chlorocuprate (I) ionic liquid: Electrochemical determination of mass transport properties. Separation and Purification Technology, 141, 31-37. https://doi.org/10.1016/j.seppur.2014.11.027

Zhao, Y., Zhao, J., Huang, Y., Zhou, Q., Zhang, X., \& Zhang, S. (2014). Toxicity of ionic liquids: database and prediction via quantitative structureactivity relationship method. Journal of Hazardous Materials, 278, 320-329. https://doi.org/10.1016/j.jhazmat.2014.06.018

Zhou, H., Shen, Y., Lv, P., Wang, J., \& Fan, J. (2013). Degradation of 1-butyl-3-methylimidazolium chloride ionic liquid by ultrasound and zero-valent iron/activated carbon. Separation and Purification Technology, 104, 208-213. https://doi.org/10.1016/j.seppur.2012.11.029

Zhu, Z., Ri, Y., Li, M., Jia, H., Wang, Y., \& Wang, Y. (2016). Extractive distillation for ethanol dehydration using imidazolium-based ionic liquids as solvents. Chemical Engineering and ProcessingProcess Intensification, 109, 190-198. https://doi.org/10.1016/j.cep.2016.09.009

Zubir, M. A., Rahimi, A. N., Zahran, M. F. I., Shahruddin, M. Z., Ibrahim, K. A., \& Abd Hamid, M. K. (2017). Systematic design of energy efficient extractive distillation column for azeotrope mixture. Energy Procedia, 142, 2636-2641. https://doi.org/10.1016/j.egypro.2017.12.203 